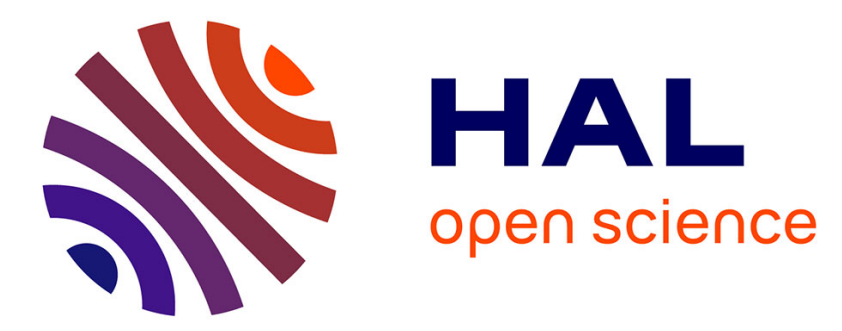

\title{
BOUND EXCITON TRANSFER IN WEAKLY DISORDERED SYSTEMS : III-V ALLOYS
}

\author{
H. Mariette, J. Kash, D. Wolford
}

\section{To cite this version:}

H. Mariette, J. Kash, D. Wolford. BOUND EXCITON TRANSFER IN WEAKLY DISORDERED SYSTEMS: III-V ALLOYS. Journal de Physique Colloques, 1985, 46 (C7), pp.C7-197-C7-201. 10.1051/jphyscol:1985737 . jpa-00225061

\section{HAL Id: jpa-00225061 https://hal.science/jpa-00225061}

Submitted on 1 Jan 1985

HAL is a multi-disciplinary open access archive for the deposit and dissemination of scientific research documents, whether they are published or not. The documents may come from teaching and research institutions in France or abroad, or from public or private research centers.
L'archive ouverte pluridisciplinaire HAL, est destinée au dépôt et à la diffusion de documents scientifiques de niveau recherche, publiés ou non, émanant des établissements d'enseignement et de recherche français ou étrangers, des laboratoires publics ou privés. 
BOUND EXCITON TRANSFER IN WEAKLY DISORDERED SYSTEMS: III-V ALLOYS ${ }^{+}$

\author{
H. Mariette ${ }^{\star}$, J.A. Kash and D.J. Wolford \\ IBM T.J. Watson Research Center, P.0. Box 218, Yorktown Heights, NY 10598, \\ U.S.A.
}

Résumé - Les mécanismes de transfert des excitons liés à l'azote dans les alliages $\mathbf{G a}_{\mathbf{x}} \mathrm{In}_{\mathrm{I}-\mathrm{x}} \mathbf{P}: \mathbf{N}$ et $\mathrm{GaAs}_{1-\mathrm{x}} \mathrm{P}_{\mathrm{x}}: \mathrm{N}$ sont observés en fonction de la température par des mesures de luminescence résolue en temps (laser picoseconde). Les résultats (saut direct entre des états localisés et piégeage multiple via les excitons libres) sont différents de ceux obtenus pour le binaire $\mathrm{GaP}: \mathrm{N}$. Nous montrons ainsi l'importance du désordre d'alliage sur la dynamique des excitons.

\begin{abstract}
Transfer mechanisms of $\mathrm{N}$-bound excitons in $\mathrm{Ga}_{\mathrm{x}} \mathrm{In}_{1-\mathrm{x}} \mathrm{P}: \mathrm{N}$ and $\mathrm{GaAs}_{1-\mathrm{x}} \mathrm{P}_{\mathrm{x}}: \mathrm{N}$ alloys are studied as a function of temperature using picosecond time resolved photoluminescence. The results, direct exciton tunneling between localized states and multiple trapping via free excitons, are different from those seen in the binary GaP:N. Thus, we demonstrate the importance of alloy disorder on the exciton dynamics.
\end{abstract}

\title{
I. INTRODUCTION
}

Ternary $A_{x} B_{1-x} C$ semiconductor alloys may be considered as model systems for investigation of the microscopic disorder inherent in alloys especially when resultstmay be compared with those of a related binary (i.e. $\mathrm{n}=0$ or $\mathrm{n}=1$ ). An example is the spectrocopic study of excitons bound to substitutional nitrogen impurities in III-V compounds. Here cw-photoluminescence (PL), PL-excitation (PLE) and time resolved luminescence spectra of $\mathrm{N}$-bound excitons are observed not only in the GaP binary but in the $\mathrm{GaAs}_{1-x} \mathrm{P}_{\mathrm{x}}$ and $\mathrm{Ga}_{x} \mathrm{In}_{1-x} \mathrm{P}$ alloys as well. In such studies, the influence of the differing local atomic configurations surrounding the nitrogen atoms has already been reported ${ }^{1,2}$. Each configuration gives rise to an excitonic state with different energy. Depending on the importance of the energy difference between these states, we observe either a broadening of the $N_{x}$ (isolated $N$ ) exciton line in $\operatorname{GaAs}_{1-x} P_{x}\left(N_{x}\right.$ band) ${ }^{1,3}$, or a splitting and broadening of this isolated $\mathrm{N}$-exciton level in $\mathrm{Ga}_{\mathrm{x}} \operatorname{In}_{1-x} \mathrm{P}\left(\mathrm{N}_{\mathrm{x}}\right.$ and $\mathrm{A}_{\mathrm{o}}$ bands) ${ }^{2}$. Moreover the exciton lines due to the repartititon of $\mathbf{N}$ impurities like neighboring pairs of $\mathbf{N}$ atoms, denoted $\mathrm{NN}_{\alpha}$, and which are prominent in GaP: $\mathrm{N}^{4}$, disappear in low-temperature PL spectra upon alloying, ${ }^{5}$, . In this paper we concentrate on the exciton dynamic of these partially disordered systems by reviewing all the mechanisms contributing to both spatial and spectral transfer of $\mathrm{N}$-bound-excitons between these discrete levels $\left(\mathbf{N N}_{\alpha}\right)$ and the inhomogenously broadened bands $\left(N_{x}, A_{o}\right)$

\section{EXPERIMENT}

Samples were excited with 20 psec pulses from a synchronously-pumped, cavity-dumped dye laser operating with coumarin 6 dye. Laser wavelengths were selected to be either resonant with the $N_{x}$ line or above the band gap. Average power and pulse repetition rates were typically $1 \mathrm{~mW}$ and $700 \mathrm{KHz}$. The samples were held at constant temperature in a He-gas-exchange cryostat. Photoluminescence was analyzed with a double-grating spectrometer, a Varian VPM 154A1 photomultiplier, and a time-correlated single photon counting system. Time resolved luminescence spectra are obtained with a time resolution of $250 \mathrm{psec}$.

\section{RESULTS}


Fig. 1 cw-photoluminescence (PL) and PL-excitation spectra (PLE) of $\mathrm{GaAs}_{1-\mathrm{x}} \mathrm{P}_{x}: \mathrm{N}, \mathrm{x}=0.96[\mathrm{~N}]=10^{18} \mathrm{~cm}^{-3}$, $\mathrm{T}=8 \mathrm{~K}$ (a) PL spectrum (solid curve) under above band gap pumping and PLE (dashed curve) observed at the LO phonon replica of the $N_{x}$ band. (b) Time-resolvedluminescence spectra under above bandgap pumping.

Experimental data at low $\mathrm{T}$ for the high energy part of the PL, PLE and time resolved luminescence spectra are presented in Fig. 1 for $\mathrm{GaAs}_{1-\mathrm{x}} \mathrm{P}_{\mathrm{x}}: \mathrm{N}^{7}$ and in Fig. 2 for $\mathrm{Ga}_{x} \mathrm{In}_{1 \times x} \mathrm{P}: \mathrm{N}^{8}$. The PLE spectra (Fig. 1a and Fig. 2a) reflect the density of states of the different isolated nitrogen centers in the alloys. We interpreted the splitting into two bands $\left(N_{x}\right.$ and $\left.A_{o}\right)$ for $G a P$-rich $G a_{x} I n_{1-x} P$, and the broadening of all the bands in both types of alloys, as resulting from the various possible atomic configurations surrounding the $\mathbf{N}$ atoms. In $\mathrm{GaAs}_{1-x} \mathbf{P}_{\mathrm{x}}: \mathbf{N}$ this local disorder occurs on the second nearest neighbor shell from the $\mathrm{N}$ impurity and the broadening of the $\mathrm{N}_{\mathrm{x}}$ band (dashed line Fig. 1a) corresponds to the envelop of the histogram arising from the 13 exciton states due to the 13 possible As-P configurations'. In contrast, in $\mathrm{Ga}_{x} \mathrm{In}_{1-x} \mathrm{P}: \mathrm{N}$ the principal energy variation of exciton bound to isolated nitrogen are due to the 5 possible Ga-In configurations which may occur statistically within the shell of the nearest neighbors to the $\mathrm{N}$ impurity. The energy difference between each of these levels is sufficiently large $(\simeq 12$ mev) that we observe a splitting of the nitrogen levels ${ }^{2}$ with each of them broadened by more distant Ga-In configurations (dashed line Fig. 2a). The PL spectra (Fig 1a and $2 \mathrm{a}$ full line) which correspond to the relaxed exciton distribution are shifted towards lower energies and the ratio $A_{0} / N_{x}$ in $G a_{x} I n_{1-x} P$ is completed inverted compared to the corresponding PLE spectra. These important differences observed between the PL and PLE spectra may be understood from the time resolved luminescence (TRL) spectra of Fig. $1 \mathrm{~b}$ and $2 \mathrm{~b}$. The TRL spectra at very short times $(<1 \mathrm{nsec})$ resemble the $\mathrm{cw}$ excitation spectra. As times increases after the laser pulse, however, the TRL spectra become progressively similar tho the $\mathrm{cw}$ luminescence one. We may also notice three main features which appear in the TRL spectra as time increase:

-(i.) The ratio between the two dominant bands $A_{0}$ (3Ga-1In neighbors) and $\mathrm{N}_{\mathrm{x}}$ (4 Ga neighbors) in GaP-rich $\mathrm{Ga}_{x} \operatorname{In}_{1-x} \mathrm{P}: \mathrm{N}$ becomes completely inverted, taking place over a period of $80 \mathrm{nsec}$ following the laser pulse (Fig. 2b)

(ii.) Most of the energy shift occurs within the first nanosecond for the $\mathrm{N}_{x}$ band in the $\mathrm{Ga}_{x} I n_{1-x} P$ (Fig. 2b) and for the higher energy part of the $N_{x}$ band in $\operatorname{GaAs}_{1-x} P_{x}$ (Fig. 1b).

Fig. 2 Same as Fig. 1 for $\mathrm{Ga}_{x} \mathrm{In}_{1-x} \mathrm{P}: \mathrm{N}, \mathrm{x}=0.99[\mathrm{~N}]=$ $10^{18} \mathrm{~cm}^{-3}, \mathrm{~T}=8 \mathrm{~K}$ (a) PL spectrum (solid curve) and PLE (dashed curve). (b) Time-resolved luminescence spectra.
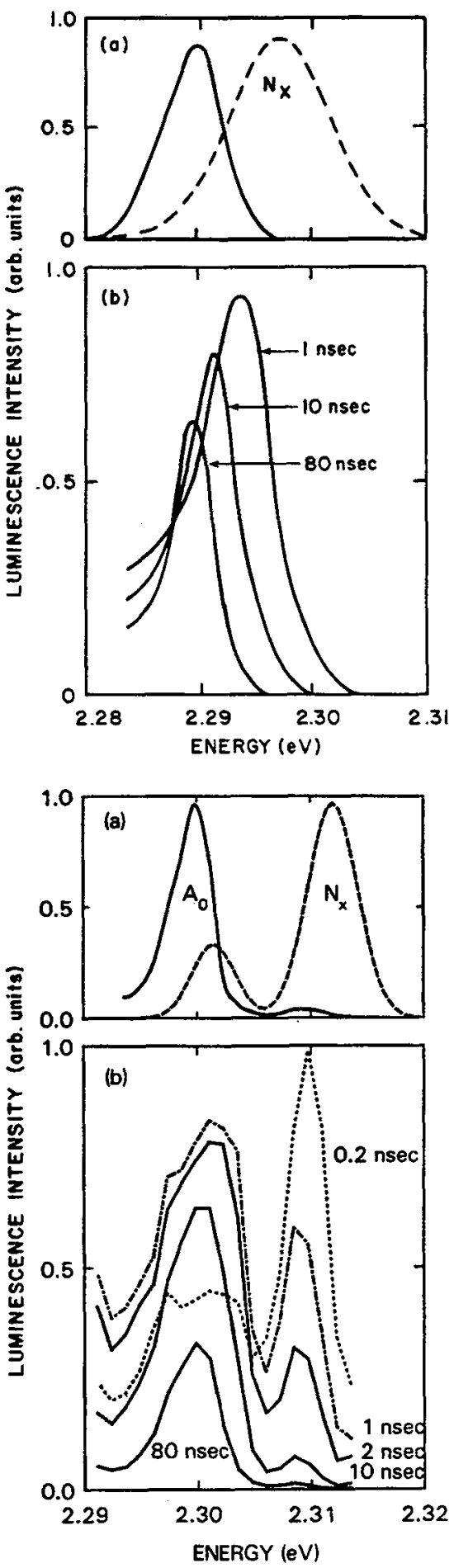
Fig. 3. cw-photoluminescence spectra of $\mathrm{GaP}: \mathrm{N}$ and $\mathrm{Ga}_{0.99} \mathrm{In}_{0.01} \mathrm{P}: \mathrm{N}$. both (a) and (b) show PL spectra at $2 \mathrm{~K}$ while (c) corresponds to $33 \mathrm{~K}$.

(iii). The dynamic energy shift within the lower energy part of the $\mathbf{N}_{\mathbf{x}}$ band in $\mathrm{GaAs}_{1-\mathrm{x}} \mathbf{P}_{\mathrm{x}^{\circ}}$ (Fig. 1b) and within the $A_{0}$ band in $\mathrm{Ga}_{x} \mathrm{In}_{1-\mathrm{x}} \mathrm{P}$ (Fig $2 \mathrm{~b}$ ) occur over a longer time scale (50 nsec).

Taken together, these low temperature results demonstrate that excitons bound to differing $\mathrm{N}$ centers transfer from site-to-site by spatial and spectral diffusion. This exciton migration (spatial diffusion) to lower energy states with energy dissipation (spectral diffusion) has been attributed to tunneling processing through the bound excitonic bands assisted by emission of appropriate acoustic phonons ${ }^{7,8}$ (this process is usually called hopping). At such low $\mathrm{T}$, an exciton trapped at a given $\mathbf{N}$ atom may tunnel only to those $\mathbf{N}$ atoms that are both spatially nearby (eg. within an exciton radius) and at the same or lower energy. By modeling ${ }^{9}$ this direct tunneling with the usual form for the hopping rate between localized states one may account for the main experimental features noted above in $\mathrm{Ga}_{x} \operatorname{In}_{1-x} \mathbf{P}$ and $\mathrm{GaAs}_{1-x} \mathrm{P}_{x}{ }^{8}$. We found in accord with the experiment, that the tunneling within the $\mathrm{N}_{\mathrm{x}}$ band in $\mathrm{Ga}_{\mathrm{x}} \mathrm{In}_{1-\mathrm{x}} \mathrm{P}$ and within the higher energy part of the $N_{x}$ band in $\mathrm{GaAs}_{1-x} P_{x}$ is much faster $\simeq 1$ $\mathrm{nsec}$ ) than that within the $\mathrm{A}_{\mathrm{o}}$ band in $\mathrm{Ga}_{\mathrm{x}} \mathrm{In}_{1-\mathrm{x}} \mathrm{P}$ and within the lower energy part of the $N_{x}$ band in $\mathrm{GaAs}_{1-x} \mathrm{P}_{x}(\simeq 50$ nsec) and between the two bands $N_{x}$ and $A_{0}$ in $G_{x} I_{1-x} P$ $(\simeq 80 \mathrm{nsec}$.). This result is a natural consequence of the smaller density of states of the $A_{0}$ centers ( $N$ surrounded by $3 \mathrm{Ga}$ and $1 \mathrm{In}$ ) in $\mathrm{GaP}$-rich $\mathrm{Ga}_{x} \mathrm{In} \mathrm{n}_{1-\mathrm{x}} \mathrm{P}$ and at the bottom of the $\mathrm{N}_{\mathrm{x}}$ band ( $\mathrm{N}$ surrounded by As-rich configurations) in GaP-rich $\mathrm{GaAs}_{1-x} \mathrm{P}_{x}$ as reflected in the PLE. Other spectral changes observed for the $\mathrm{N}_{\mathrm{x}}$ and $\mathrm{A}_{\mathrm{o}}$ PL-bands as a function of $\mathrm{N}$ concentration and excitation power ${ }^{10}$ are consistent with this hopping model.

This direct tunneling assisted by phonons was first observed in GaP:N between the $\mathrm{NN}_{\alpha}$ pair levels ${ }^{11}$ which dominate the PL spectra at low temperature (Fig. 3a). In that case a stochastic approach of exciton tunneling among the two nearest neighbors of a given center ${ }^{12}$ (triplet configuration) account for the strong intensities of all the $\mathrm{NN}_{\alpha}$ lines at low temperature. In contrast, in the alloys we do not see any efficient $\mathrm{N}_{\mathrm{x}} \rightarrow \mathrm{NN}_{\alpha}$ transfer at low temperature (Fig. 3b). However, as the temperature

Fig. 4. Kinetics of the $\mathrm{NN}_{1}$ luminescence at different temperatures with the laser excitation in the $\mathrm{N}_{\mathrm{x}}$ band, for $\mathrm{GaAs}_{0.04} \mathrm{P}_{0.96}: \mathrm{N},[\mathrm{N}]=10^{18} \mathrm{~cm}^{-3}(\mathrm{a})$, and $\mathrm{Ga}_{0.99} \mathrm{In}_{0.01} \mathrm{P}: \mathrm{N}$, $[\mathrm{N}]=10^{18} \mathrm{~cm}^{-3}(\mathrm{~b})$
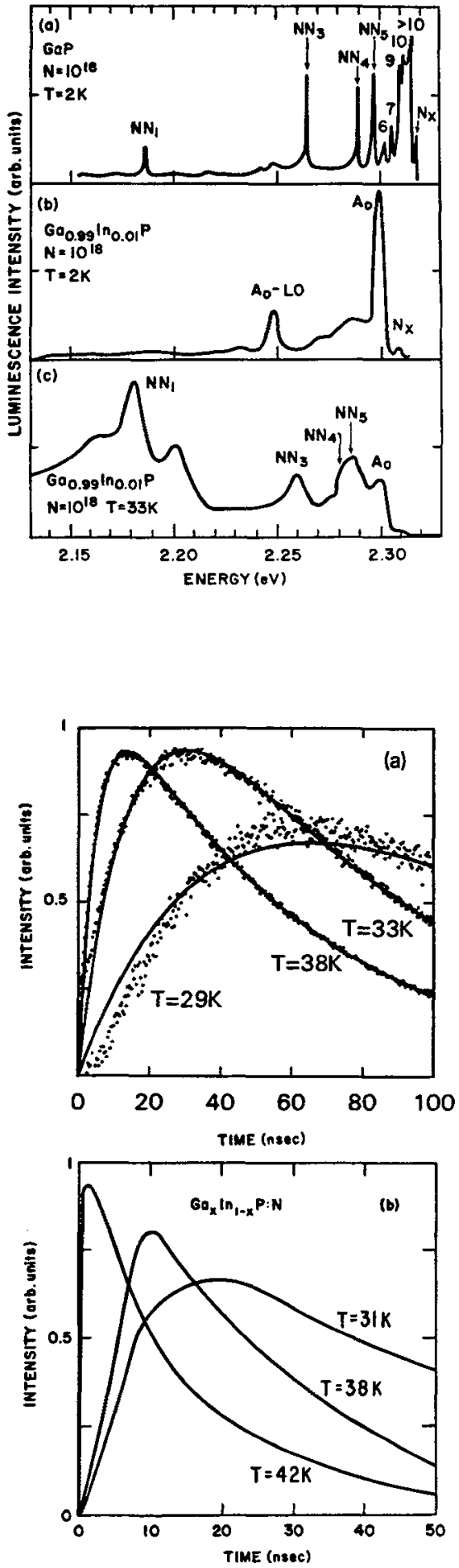
is raised, the $\mathrm{NN}_{a}$ pair lines appear in the PL spectra of both $\mathrm{GaAs}_{1-\mathrm{x}} \mathrm{P}_{\mathrm{x}}{ }^{13}$ and $\mathrm{Ga}_{\mathrm{x}} \mathrm{In}_{1-\mathrm{x}} \mathrm{P}$ (Fig 3c) while the $N_{x}$ and $A_{o}$ bands rapidly diminish. This evolution could be explained by the time dependence study of the $\mathrm{NN}_{1}$ luminescence intensity as a function of $\mathrm{T}$ (Fig. 4). The main result is that, as the temperature is increased, the luminescence intensity maximum shifts to shorter times, corresponding to a sharply decreasing of the $\mathrm{NN}_{1}$ luminescence risetime ${ }^{13}$. For example, for $\mathrm{GaAs}_{0.04} \mathrm{P}_{0.96}$, the $\mathrm{N}_{\mathrm{X}} \rightarrow \mathrm{NN}_{1}$ transfer takes 150 nsec at $30 \mathrm{~K}$ and only $400 \mathrm{psec}$ at $50 \mathrm{~K}$. At lower $\mathrm{T}$ the $\mathrm{NN}_{1}$ emission is too weak compared to the underlying $\mathrm{N}_{\mathrm{x}}$ background. At $\mathrm{T}=50 \mathrm{~K}$, the risetime is sufficiently short as to approaching the system resolution (250 psec). These results clearly demonstrate that with increasing temperature, the $\mathbf{N}_{\mathrm{x}} \rightarrow \mathrm{NN}_{1}$ interband transfer rate progressively increases, i.e. it becomes thermally activated. By studying this $T$-dependence ${ }^{13}$ we concluded that the thermal energy (kT) greatly increases the effective spatial diffusion of the isolated $\mathrm{N}$-bound excitons, a consequence we attributed to two coexisting mechanisms. The first is multiple trapping in which a $\mathrm{N}$-exciton may be thermally excited from the isolated center to extended states (ie. free excitons of free carriers) with subsequent retrapping at either a different isolated $\mathbf{N}$-site or an $\mathbf{N N}_{\alpha}$ site. The second process is similar to variable range hopping and results from excitons tunneling solely within the $N_{x}$ and $A_{o}$ bands until they reach an $\mathbf{N N}_{\alpha}$ site on which they can directly tunnel. In the alloy, due to the disorder broadening, this direct tunneling must be activated thermally to proceed efficiently. By contrast, in GaP:N, because the $\mathbf{N}_{\mathrm{x}}$ line is mainly monoenergetic, the direct tunneling from $\mathbf{N}_{\mathrm{x}}$ to $\mathbf{N N}_{\alpha}$ is always unimpeded and efficient even at low temperature. Therefore, in GaP:N the PL intensity increases observed for $\mathrm{NN}_{\alpha}$ pair lines with temperature ${ }^{12,14}$ before the thermal quenching ${ }^{15}$ are mainly due to multiple trapping.

To summarize we illustrate the differences between the exciton transfer mechanisms in the alloys compared to the binary in Fig. 5. At low temperature, hopping between differing localized states is the dominant process in both the alloy and the binary. However, for GaP: $\mathbf{N}$ the spatial diffusion of the excitons within the very narrow $\mathbf{N}_{\mathrm{x}}$ line is such that the isolated $\mathrm{N}$ bound exciton can tunnel efficiently to the $\mathbf{N N}_{\alpha}$ pairs (Fig. 5a). In the alloys, however, because of the disorder-broadening and splitting of the isolated nitrogen levels, the excitons soon become trapped at the sites of lower energy (Fig. 5b). Therefore the N-bound exciton spatial diffusion is greatly reduced and exciton tunneling to $\mathrm{NN}_{\alpha}$ pairs is inhibited. As the temperature increases multiple trapping processes are thermal activated in both the alloys and the binary (Fig. $5 \mathrm{c}$ and d). However, in the alloy the direct tunneling is also strongly temperature dependent (variable range hopping) and contributes efficiently to the observed increasing of the $\mathbf{N}_{x}\left(A_{o}\right) \rightarrow \mathbf{N N}_{\alpha}$ transfer.

Fig. 5. N-bound exciton transfer mechanisms in alloys (b and d) compared to the binary (a and c)

(a) GaP low T: $\mathrm{N}_{\mathrm{x}} \rightarrow \mathrm{NN}_{\alpha}$ transfer by hopping between different equivalent $\mathrm{N}_{\mathrm{x}}$ states until the excitons reach an $\mathrm{NN}_{\alpha}$ state on which they hop.

(b) Alloys low $T$ : intraband and interband transfer within and between the $\mathrm{N}_{\mathrm{x}}$ and $\mathrm{A}_{\mathrm{o}}$ bands due to the statistical distribution of the energy levels by the alloy local disorder.

(c) GaP, T > 10K: $\mathrm{N}_{\mathrm{x}} \rightarrow \mathrm{NN}_{\alpha}$ transfer by hopping and multiple trapping through extended states (free excitons).

(d) Alloys, $\mathrm{T}>10 \mathrm{~K}: \mathrm{N}_{\mathrm{x}}\left(\mathrm{A}_{\circ}\right) \rightarrow \mathrm{NN}_{\alpha}$ transfer by variable range hopping through the alloying states and miltiple trapping through extended states (FX)
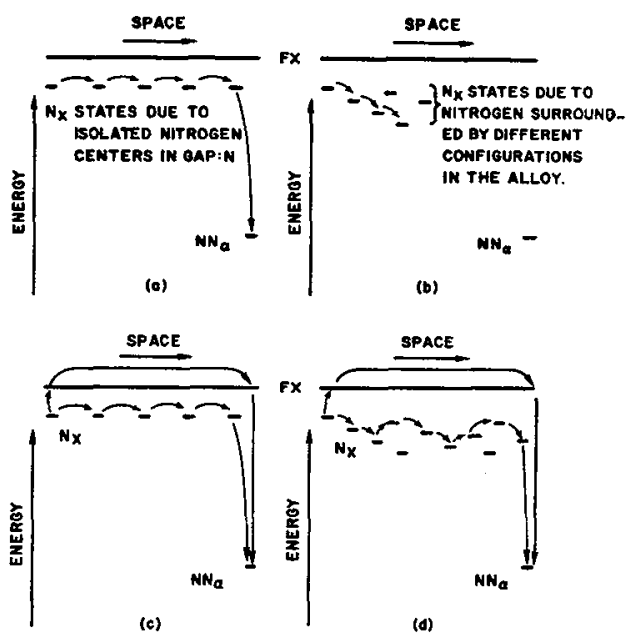

(d) 


\section{CONCLUSION}

We demonstrate and explain three distinct types of exciton transfer for excitons bound to substitutional $\mathrm{N}$ traps in GaAs$s_{1-x} P_{x}: N$ and $\mathrm{Ga}_{x} \mathrm{In}_{1-x} \mathrm{P}: \mathrm{N}$. These transfer mechanisms, related to the alloy disorder, are observed by picosecond time-resolved photoluminescence, depending on temperature. The first one occurs at low temperatures, when excitons tunnel only to lower energy sites within the band of excitons bound to isolated nitrogen $\left(\mathrm{N}_{\mathrm{x}}\right)$, broadened in the $\mathrm{GaAs}_{1-\mathrm{x}} \mathrm{P}_{\mathrm{x}}: \mathrm{N}$ alloy by different As-P local configurations around nitrogen atoms (disorder broadening). The same direct tunneling is also observed in $\mathrm{Ga}_{x} \mathrm{In}_{1-x} \mathrm{P}: \mathrm{N}$. Here, however, the disorder broadening gives rise to several bands corresponding to different nearest neighbor Ga-In configurations.

The second and third types of transfer are exciton tunneling form the $\mathrm{N}_{\mathrm{x}}$ band to deeper $\mathrm{NN}_{\alpha}$ traps. GaP shows such $\mathbf{N}_{x} \rightarrow \mathbf{N N}_{\kappa}$ transfer at low temperature; alloys do not. As the temperature is increased, however, this transfer appears in alloys with a transfer time which decreases sharply with $T$. Thus, the $N_{x}\left(A_{o}\right) \rightarrow$ $\mathrm{NN}_{\mathrm{r}}$ interband transfer in alloys is thermally activated. This interband transfer happens either directly by variable range hopping, or indirectly via free excitons by multiple trapping. These two mechanisms are active here in the temperature range $30-50 \mathrm{~K}$.

These results, direct tunneling between and within the $\mathbf{N}_{x}$ and $A_{o}$ bands, and the $N_{x}\left(A_{o}\right) \rightarrow N_{\alpha}$ transfers are different from those seen in GaP:N. Compared to the binary, the exciton spatial diffusion is greatly reduced in the alloy due to lower energy states which arise from the random disorder broadening and splitting. Thus, we show the importance of alloy disorder on the exciton dynamics.

\section{REFERENCES}

+We gratefully acknowledge support by the ONR (N00014-80-C-0376)

^ On leave from Laboratoire de Physique des Solides, CNRS, Meudon- Bellevue, France

1. Mariette, H., Chevallier, J. and Leroux-Hugon, P., Solid State Commun. 29 (1979); Phys. Rev. B21 (1980) 5706.

2. Mariette, H., Solid State Commun. $\underline{38}$ (1981) 1193; Mbaye, A. and Mariette, H., J. Phys. $\underline{\text { C17 }}$ (1984) 6663.

3. Wolford, D.J., Streetman, B.G. and Thompson, J., Phys. Sol., Jpn. Suppl. A49 (1980) 223.

4. Thomas, D.J. and Hopfield, J.J., Phys Rev. 150 (1966) 680.

5. Wolford, D.J., Streetman, B.G., Nelson; R.J. and Holonyak, N. Jr., Solid State Commun. 19 (1976) 741.

6. Nelson, R.J. and Holonyak, N. Jr., J. Phys. Chem. Solids 37 (1976) 629; Mariette, H. and Chevallier, J., J. Appl. Phys. $\underline{48}$ (1977) 1200.

7. Collet, J.H., Kash, J.A., Wolford, D.J. and Thompson, J., J. Phys C16 (1983) 1283.

8. Mariette, H., Kash, J.A., Wolford, D.J. and Marbeuf, A., Phys Rev. B31 (1985) 5217.

9. Kash, J.A., Phys. Rev. B29 (1984) 7069.

10. Stegmann, R., Nurdinov, N.R., Yunovich, A.E. and Oelgart, G., Phys. State. Sol. A62 (1980) K49., Mariette, H., Thierry-Mieg, V., Chevallier, J. and Leroux-Hugon P. Physica 117B, 118B (1983) 102.

11. Wiesner, P.J., Street, R.A. and Wolf, H.D., Phys Rev. Lett. 35 (1975) 1366.

12. Leroux-Hugon, P. and Mariette, H., Phys Rev. B30 (1964) 1622.

13. Kash, J.A., Mariette, H., Wolford, D.J. to be published in Phys. Rev. B

14. Nurdinov, N. and Munir, M., Sov. Phys. Semicond. 15 (1981) 1210.

15. Sturge, M.D., Cohen, E. and Rodgers, K., Phys Rev. B15 (1977) 3169. 